\title{
Total arterial revascularization with composite skeletonized gastroepiploic artery graft in off-pump coronary artery bypass grafting
}

\author{
Hiroyuki Kamiya, MD \\ Go Watanabe, MD \\ Hirofumi Takemura, MD \\ Shigeyuki Tomita, MD \\ Hiroshi Nagamine, MD \\ Taro Kanamori, MD
}

From the Department of General and Cardiothoracic Surgery, Kanazawa University Hospital, Kanazawa, Japan.

Received for publication July 17, 2003; revisions requested Sept 23, 2003; revisions received Sept 30, 2003; accepted for publication Nov 20, 2003.

Address for reprints: Hiroyuki Kamiya, MD, Department of General and Cardiothoracic Surgery, Kanazawa University Hospital, Takaramachi 13-1, Kanazawa, Japan 920-8641 (E-mail: hkamiya88@yahoo. co.jp)

J Thorac Cardiovasc Surg 2004;127:1151-7

$0022-5223 / \$ 30.00$

Copyright () 2004 by The American Association for Thoracic Surgery

doi:10.1016/j.jtcvs.2003.09.057
Background: Total arterial revascularization in coronary artery bypass grafting has recently become of great interest to many surgeons. At the same time, off-pump coronary bypass grafting has also become a popular procedure because of its low morbidity and mortality. Here we report our recent series of off-pump coronary bypass grafting performed with a grafting technique we developed by using the skeletonized gastroepiploic artery and the radial artery composite graft to achieve total arterial revascularization.

Methods: From September 2000 to April 2003, 98 patients underwent total arterial revascularization with the skeletonized gastroepiploic artery and radial artery composite graft on the beating heart. We used the gastroepiploic artery graft of choice in patients with a right coronary artery lesion. When multiple grafting was required in inferior, posterolateral, or lateral ventricular walls and the gastroepiploic artery graft was too short to cover these areas, we used the composite grafting technique.

Results: There were no in-hospital deaths and there was no severe morbidity among the study patients. Postoperative angiography showed graft occlusion at the anastomosis site between the gastroepiploic and radial arteries. The patency rate of the gastroepiploic arterial composite graft was 98.3\% (118/120 distal anastomoses).

Conclusions: A composite graft with the skeletonized gastroepiploic artery and the radial artery ensured sufficient caliber size and length for myocardial revascularization on inferior, posterolateral, and lateral ventricular walls. This composite graft can be used safely and effectively even in off-pump coronary bypass surgery with excellent early clinical and angiographic outcome in selected patients, although longer follow-up periods are necessary to draw definitive conclusions.

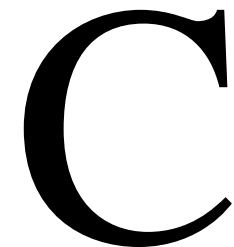

onventional coronary artery bypass grafting (CABG) has been performed with a single internal thoracic artery (ITA) graft to the left anterior descending coronary artery (LAD) and additional saphenous vein grafts by using cardiopulmonary bypass with cardioplegic arrest. However, with the increase in saphenous vein graft disease, surgeons have begun to use additional arterial grafts for $\mathrm{CABG},{ }^{1,2}$ and several studies have demonstrated that the use of multiple arterial grafts clearly improves the long-term outcome of patients undergoing CABG. ${ }^{3,4}$ Moreover, total arterial revascularization in $\mathrm{CABG}$ has recently become of great interest to many surgeons. ${ }^{5-8}$ At the same time, off-pump CABG (OPCAB) has become popular because of its low morbidity and mortality. ${ }^{9-11}$ However, to our knowledge, there are only a few reports on $\mathrm{OPCAB}$ for total arterial revasculariza- 
TABLE 1. Patient characteristics and operative data

\begin{tabular}{|c|c|c|c|}
\hline Variable & $\begin{array}{c}\text { Group } 1 \\
(n=98)\end{array}$ & $\begin{array}{l}\text { Group } 2 \\
(\mathrm{n}=70)\end{array}$ & $P$ value \\
\hline Age (y) & $68 \pm 10$ & $66 \pm 9$ & .71 \\
\hline Male & $80(82 \%)$ & $51(73 \%)$ & .19 \\
\hline Prior $\mathrm{Ml}$ & $82(84 \%)$ & $58(83 \%)$ & .89 \\
\hline Left main $\geq 50 \%$ & $40(41 \%)$ & $32(46 \%)$ & .52 \\
\hline No. of diseased vessels & $2.7 \pm 0.5$ & $2.3 \pm 0.5$ & .12 \\
\hline No. of distal anastomoses & $3.4 \pm 0.7$ & $2.7 \pm 0.6$ & .26 \\
\hline No. of distal anastomoses from GEA inlet & $2.1 \pm 0.4$ & $1.1 \pm 0.4$ & .001 \\
\hline Single grafting & & 61 & \\
\hline Double grafting & & 8 & \\
\hline Triple grafting & & 1 & \\
\hline I composite & 94 & & \\
\hline Double grafting & 88 & & \\
\hline Triple grafting & 6 & & \\
\hline Y composite & 4 & & \\
\hline Double grafting & 4 & & \\
\hline No. of distal anastomoses from LITA inlet & $1.2 \pm 0.3$ & $1.2 \pm 0.4$ & .92 \\
\hline No. of distal anastomoses from RITA inlet & $0.1 \pm 0.2$ & $0.1 \pm 0.3$ & .89 \\
\hline Operative time (min) & $192 \pm 34$ & $186 \pm 42$ & .86 \\
\hline ICU stay (h) & $29.1 \pm 11.2$ & $28.3 \pm 12.3$ & .79 \\
\hline Hospital stay $(d)$ & $14.3 \pm 9.6$ & $15.0 \pm 10.3$ & .80 \\
\hline
\end{tabular}

Data are $\mathrm{n}$ or mean \pm SD. GEA, Gastroepiploic artery; ICU, intensive care unit; LITA, left internal thoracic artery; MI, myocardial infarction; RITA, right internal thoracic artery.

tion. ${ }^{12-14}$ Here we report our recent series of OPCAB performed with a grafting technique that we developed by using the skeletonized gastroepiploic artery (GEA) and the radial artery (RA) composite graft to achieve total arterial revascularization.

\section{Materials and Methods \\ Patients}

From September 2000 to April 2003, 407 patients underwent OPCAB operations in our institute. Among these patients, 300 patients $(74 \%)$ received total arterial revascularization. In these 300 patients, skeletonized GEA grafting was performed for 168 patients $(41 \%$; 168/407), and skeletonized GEA and the RA composite grafts were used for 98 patients (24\%; 98/407). Total arterial revascularization was our grafting strategy of choice for patients younger than 80 years in elective cases. We used the GEA graft of choice in patients with right coronary artery lesions. When multiple grafting was required in the inferior, posterolateral, or lateral ventricular walls and the GEA graft was too short to cover these areas, we used the composite grafting technique. The patients who received skeletonized GEA grafting as a composite graft with the RA were categorized into group $1(n=98)$, and the patients who received skeletonized GEA grafting not in a composite fashion were categorized into group $2(\mathrm{n}=70)$. The clinical characteristics of the patients are summarized in Table 1.

\section{Surgical Technique}

All operations were performed through a median sternotomy incision. The ITAs and the RAs were harvested as pedicles by using a conventional technique with cautery. The GEA was harvested as a wide pedicle including the artery, veins, and fat by using the
Harmonic Scalpel with coagulating shears (Ethicon Endosurgery, Cincinnati, Ohio) and was then skeletonized. After administration of heparin $1.5 \mathrm{mg} / \mathrm{kg}$, the distal site of the GEA was cut, and the pedicled GEA was pulled out from the intra-abdominal space. This made further manipulation very easy. Olprinone hydrochloride (5 $\mathrm{mg}$ of olprinone in $100 \mathrm{~mL}$ of normal saline) was administrated into the GEA intraluminally. After that, the GEA was skeletonized by using the same apparatus. The GEA was usually narrow before skeletonization, but the size of the GEA increased after skeletonization in most cases. The narrow distal sections of the GEA were abandoned, and only sections with large calibers of more than 2.0 $\mathrm{mm}$ were used.

The pericardium was opened with an inverted T-shaped incision after harvesting of the arterial grafts. The right pleural space was opened to create a space for a vertically placed heart, to minimize hemodynamic compromise. After evaluation of coronary artery status, the composite grafts were made with 8-0 polypropylene running sutures. An I composite graft with skeletonized GEA and the RA was adopted in 88 patients, and a Y composite graft was adopted in 6 patients (Table 1). In all cases, sufficient free flow from the composite graft was confirmed. If necessary, additional Y composite grafts were made with the ITA and the RA.

Two deep pericardial sutures were placed to facilitate pericardial retraction for cardiac elevation and exposure. The heart was stabilized with an Octopus 3 stabilizer (Medtronic Inc, Minneapolis, Minn) or a Doughnut stabilizer (Fukuda Denshi, Tokyo, Japan). To maintain myocardial perfusion during anastomoses, our originally developed coronary active perfusion system was used in all cases. ${ }^{15-17}$ The most critical vessel— the LAD in most patients-was revascularized first to provide a backup to other areas. Distal anastomoses were performed with 8-0 polypropylene running sutures. 
(A)

I Composite (OM1, PD)

$$
\mathrm{n}=19
$$

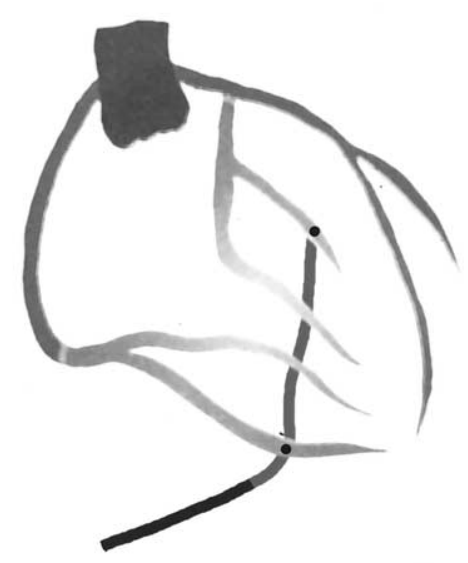

(C)

I Composite (PL, PD)

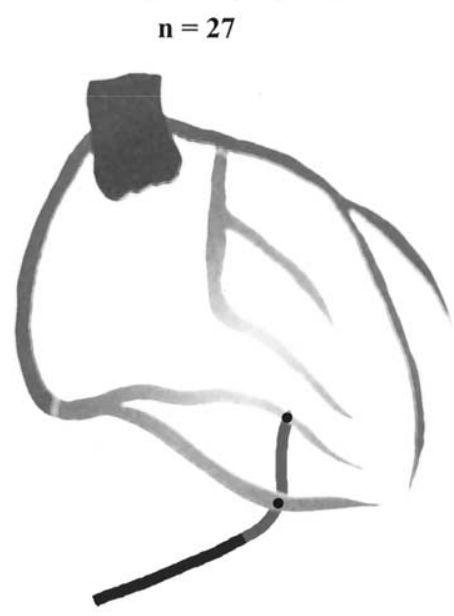

(B)

I Composite (OM2, PD)

$$
\mathrm{n}=32
$$

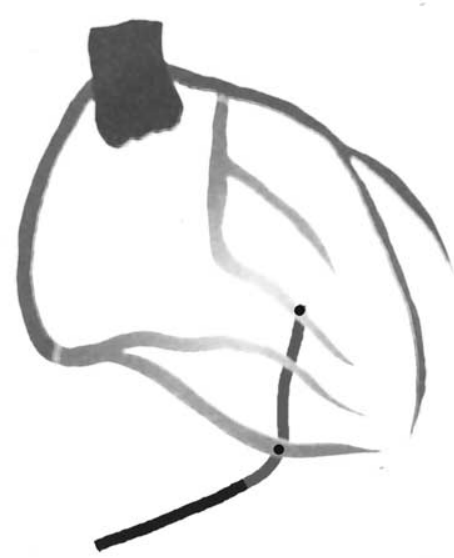

(D)

I Composite (OM2, PL) $\mathrm{n}=\mathbf{1 0}$

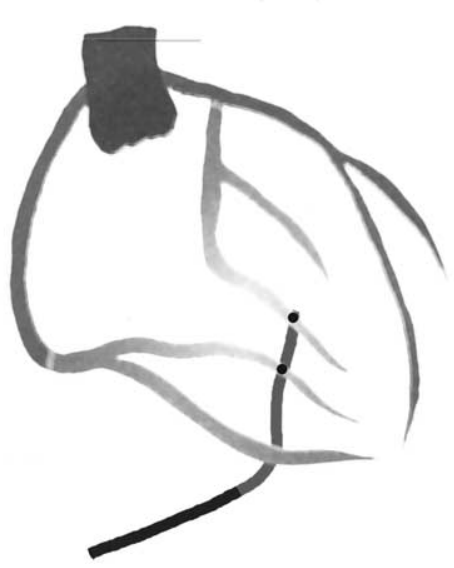

Figure 1. Double grafting using the I composite graft with the skeletonized gastroepiploic artery and the radial artery. $O M$, Obtuse marginal coronary artery; $P D$, posterodescending coronary artery; $P L$, posterolateral coronary artery.

\section{Grafting Strategies}

The left ITA was anastomosed to the LAD in all patients. If necessary, a Y composite graft with the left ITA and the RA was adopted to anastomose to the diagonal branch. Coronary arteries on the inferior and/or posterolateral walls, including the posterodescending, posterolateral, and obtuse marginal coronary arteries, were revascularized with skeletonized GEA or composite graft with skeletonized GEA and RA. Proximal anastomosis on the ascending aorta was not performed in any patient. The distributions of distal target sites anastomosed by the composite grafts are shown in Figures 1 to 3.

\section{Angiographic Assessment}

The necessity and significance of postoperative coronary angiography were explained to all patients, and angiography was per- formed if patients agreed. Postoperative angiography was performed approximately 2 weeks after the operation in 60 patients $(61 \%)$. An example of postoperative angiography is shown in Figure 4.

\section{Statistical Analysis}

Results were expressed as mean $\pm \mathrm{SD}$. Statistical analysis was performed with Student $t$ tests for continuous variables or with $\chi^{2}$ tests (Fisher exact tests if $\mathrm{n}$ was $<5$ ) for categorical variables. All statistical analyses were performed with SPSS 10.0 software (SPSS Japan Inc, Tokyo, Japan).

\section{Results}

There were no in-hospital deaths among the study patients. None of the patients had low cardiac output, perioperative 
(A)

Y Composite (OM1, PD)
$n=3$

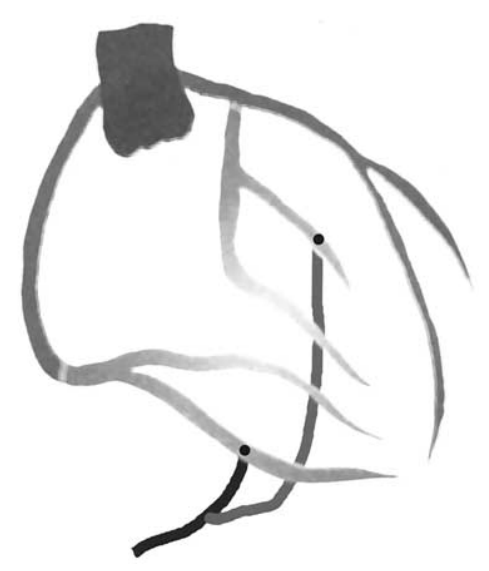

(B)

Y Composite (OM2, PD)

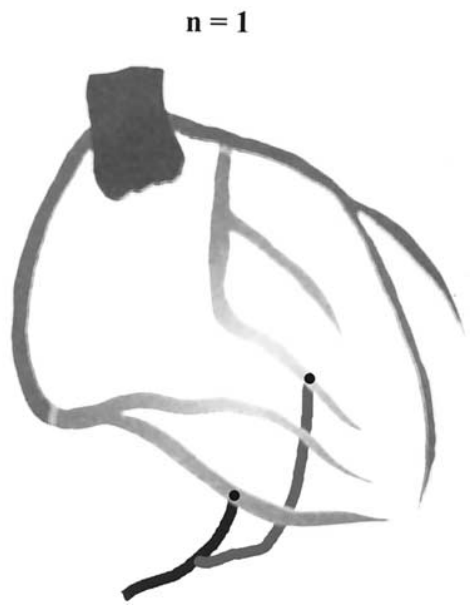

Figure 2. Triple grafting using the I composite graft with the skeletonized gastroepiploic artery and the radial artery. $O M$, Obtuse marginal coronary artery; $P D$, posterodescending coronary artery.

(A)

I Composite (OM1, PL, PD)

$$
\mathbf{n}=\mathbf{3}
$$

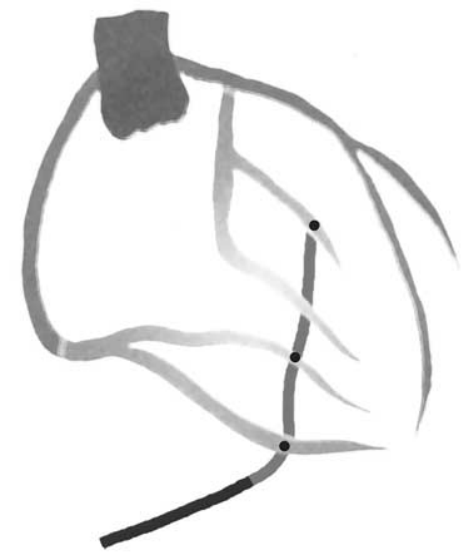

(B)

I Composite (OM1, OM2, PD)

$$
\mathbf{n}=\mathbf{3}
$$

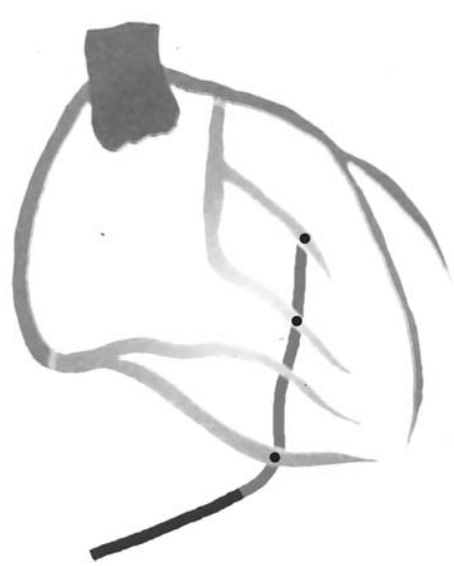

Figure 3. Double grafting using the $Y$ composite graft with the skeletonized gastroepiploic artery and the radial artery. $O M$, Obtuse marginal coronary artery; $P D$, posterodescending coronary artery; $P L$, posterolateral coronary artery.

myocardial infarction, newly developed cerebrovascular events, or sternal wound infection. One patient needed reoperation for postoperative bleeding (group 1). Postoperative atrial fibrillation occurred in 8 patients $(8 \%)$ in group 1 and $7(10 \%)$ in group 2. Postoperative angiography showed graft occlusion at the anastomosis site between the GEA and the RA in 2 patients ( 1 at the end-to-end anastomosis site and the other at the side-to-side anastomosis site) and showed flow competition between the composite graft and the native coronary artery in 2 patients in group 1 . In other patients, no graft stenosis was observed in group 1. In group 2, 1 graft occlusion was observed at the distal anastomosis site (end to side) in 1 patient, and $75 \%$ stenosis was observed at the distal anastomosis site in another patient. Other grafts, including the ITA, the ITA composite graft, and the GEA composite grafts, were all patent. The patency rate of the GEA composite graft was $98.3 \%$ (118/120 distal anastomoses) in group 1 , and that of the GEA graft was $97.1 \%$ (33/34 distal anastomosis) in group $2(P=$ $.64)$. 


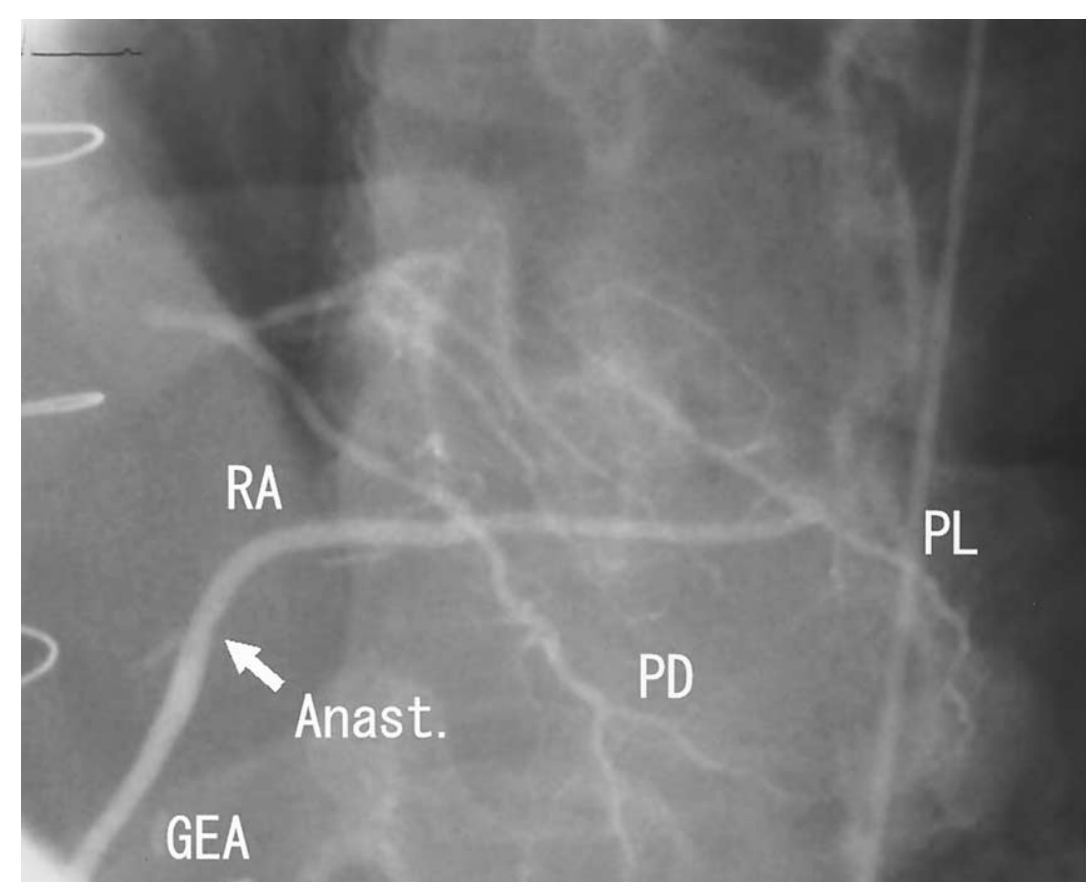

Figure 4. Postoperative angiography of the I composite graft with the skeletonized gastroepiploic artery and the radial artery. PD, Posterodescending coronary artery; $P L$, posterolateral coronary artery; Anast., anastomosis.

The follow-up was $100 \%$ complete. The mean follow-up duration was $16.3 \pm 8.4$ months in both groups. There was 1 cardiac death (due to heart failure at 9 months after the operation) in group 1 . There was no myocardial infarction in either group. There were 3 other noncardiac deaths ( 1 due to cerebral infarction, 1 due to cancer, and 1 from old age) in group 1, and there was 1 (due to cancer) in group 2 .

\section{Discussion}

This study demonstrates that skeletonized GEA and RA composite grafts can be used safely and effectively in OP$\mathrm{CAB}$ surgery for myocardial revascularization on the inferior, posterolateral, and lateral ventricular walls with excellent early clinical and angiographic outcome. The concept of total arterial myocardial revascularization with composite grafts is not novel, ${ }^{5,7,8}$ but surgeons are still hesitant to perform OPCAB surgery with multiple arterial grafts because of technique difficulties and lack of angiographic results. However, recently several reports on OPCAB for total arterial revascularization with composite grafts have been presented. Quigley and colleagues ${ }^{12}$ reported several patterns of composite grafts, including I, Y, U, and $\mathrm{K}$ grafts, with mainly ITAs and the RA. Kim and colleagues ${ }^{14}$ demonstrated aggressive use of bilateral skeletonized ITA grafts in OPCAB and achieved total arterial revascularization in $92 \%$ of patients. Similar to their reports, we consider that total arterial revascularization can be safely performed by $\mathrm{OPCAB}$ surgery with composite grafts and that this grafting technique will become the procedure of choice as data on early and late outcome in both clinical and angiographic aspects become available.

In this series, we applied composite grafting by using skeletonized GEA and RA. We developed this technique to ensure sufficient caliber size and length of the GEA for composite grafts. The luminal diameter of the GEA at the distal site is usually much narrower than at the proximal segment. Skeletonization of the GEA increases the luminal diameter by some degree, but it is not always enough, especially at the distal segment. In this series, the number of distal anastomoses from the GEA inlet in group 1 was greater than in group 2, without an increase in any adverse event. This suggests that a skeletonized GEA and the RA composite graft can be an effective choice of strategy when multiple grafting is required on inferior, posterolateral, or lateral ventricular walls.

Ochi and associates ${ }^{18,19}$ reported that the GEA graft may be less capable of perfusing the coronary artery than the ITA graft because the GEA is a third branch of the abdominal aorta, whereas the ITA is a second branch of the aortic arch. They recommended that the GEA graft should have a large luminal diameter $(2-3 \mathrm{~mm})$ at its anastomotic point to generate adequate perfusion pressure. In this series, distal sites of the GEA that had diameters less than $2 \mathrm{~mm}$ even after dilation by skeletonization were abandoned, and in most cases they were anastomosed to the RA in an end-toend fashion. The RA usually has a sufficient caliber size 
even without skeletonization, ${ }^{20}$ and there were no caliber mismatches at the sites of the anastomoses between the skeletonized GEA and the RA in our series.

The composite grafts used in this study had enough length that reached as far as the lateral region, and this made it possible to perform multiple grafting at the area from the inferior to the lateral region, mainly with the sequential grafting technique. At present, surgeons are rather hesitant to use the sequential grafting method for OPCAB. AlRuzzeh and associates ${ }^{21}$ reported their early experience in 2002 of 45 patients who underwent OPCAB with the sequential grafting technique, with excellent results. They emphasized that fine exposure and stabilization made sequential anastomoses technically feasible, with satisfactory outcome. We also consider that exposure and stabilization are the key techniques for OPCAB surgery, and when they are successfully achieved, sequential grafting can be safely and effectively applied even to OPCAB.

Several surgeons have emphasized the advantage of ITA-RA composite grafting. ${ }^{5,7,12,22}$ Sundt and colleagues ${ }^{22}$ reported that 649 patients underwent CABG with an ITA and $\mathrm{RA}$ in a $\mathrm{T}$-graft configuration and commented that complete arterial revascularization could be achieved in most patients by using a single ITA and single RA. However, others have cautioned against the potentially catastrophic consequences of acute hypoperfusion resulting from inadequate ITA flow. ${ }^{23,24}$ We consider that ITA grafting to the LAD is the key grafting in CABG surgery; therefore, we have used ITA or ITA-RA composite grafts only to the anterior and anteroseptal walls, considering the possibility of causing the hypoperfusion phenomenon.

It must be noted that there have been several reports of flow competition between the native coronary artery and the GEA graft. ${ }^{25}$ However, Sato and colleagues ${ }^{26}$ have reported 13 successful cases of CABG with GEA-RA composite grafts. They reported that they had no experience of hypoperfusion in the posterolateral or inferior areas, and postoperative angiography revealed widely patent composite grafts without any flow insufficiency. Similar to their report, early clinical and angiographic outcomes in this series were excellent, although we performed no quantitative study regarding flow dynamics of the composite graft. Initially, we proposed that nearly all patients receive postoperative angiograms. With experience, however, since April 2002, we have been recommending that patients undergo postoperative angiogram only when we are anxious over the quality of the anastomoses. From our early clinical results, we consider that composite grafts with skeletonized GEA and the RA can provide sufficient perfusion in both the left circumflex coronary artery and the right coronary artery systems. However, our results should be confirmed by further clinical follow-up of the patients.
In conclusion, composite grafts with skeletonized GEA and the RA ensured sufficient caliber size and length for myocardial revascularization on inferior, posterolateral, or lateral ventricular walls. On the basis of this study, we consider that this composite graft could be used safely and effectively even in OPCAB surgery, with excellent early clinical and angiographic outcome in selected patients. However, long-term follow-up is necessary to draw definitive conclusions.

We thank Gaia Hoerner for helping in the preparation of the manuscript.

\section{References}

1. Reardon MJ, Conklin LD, Reardon PR, Baldwin JC. Coronary artery bypass conduits: review of current status. J Cardiovasc Surg (Torino). 1997;38:201-9.

2. Lytle BW, Loop FD, Taylor PC, Simpfendorfer C, Kramer JR, Ratliff $\mathrm{NB}$, et al. Vein graft disease: the clinical impact of stenosis in saphenous vein bypass grafts to coronary arteries. J Thorac Cardiovasc Surg. 1992;103:831-40.

3. Barner HB, Sundt TM III. Multiple arterial grafts and survival. Curr Opin Cardiol. 1999;14:501-5.

4. Pick AW, Orszulak TA, Anderson BJ, Schaff HV. Single versus bilateral internal mammary artery graft: 10 year outcome analysis. Ann Thorac Surg. 1997;64:599-605.

5. Weinshelbaum EE, Gabe ED, Macchia A, Smimmo R, Suarez LD. Total myocardial revascularization with arterial conduits: radial artery combined with internal thoracic arteries. J Thorac Cardiovasc Surg. 1997;114:911-6

6. Lytle JA, Blackstone EH, Loop FD, Houghtaling PL, Arnold JH, Akhrass R, et al. Two internal thoracic artery grafts are better than one. J Thorac Cardiovasc Surg. 1999;117:855-72.

7. Chistensen JB, Lund JT, Kassis E, Kelbeak H. Complete arterial coronary revascularization using radial artery conduit for double thoracic artery inlet flow: arterial sling operation. Eur $J$ Cardiothorac Surg. 2002;21:391-4.

8. Muneretto C, Negri A, Manfredi J, Terrini A, Rodella G, Elqarra S, et al. Safety and usefulness of composite grafts for total arterial myocardial revascularization: a prospective randomized evaluation. $J$ Thorac Cardiovasc Surg. 2003;125:826-35.

9. Buffolo E, de Andrade CS, Branco JN, Teles CA, Aguiar LF, Gomes WJ. Coronary artery bypass grafting without cardiopulmonary bypass. Ann Thorac Surg. 1996;61:63-6.

10. Calafiore AM, Angelini GD, Bergsland J, Salerno TA. Minimally invasive coronary artery bypass grafting. Ann Thorac Surg. 1996;62: $1545-8$.

11. Watanabe G, Misaki T, Kotoh K, Kawakami K, Yamashita A, Ueyama K. Multiple minimally invasive direct coronary artery bypass grafting for the complete revascularization of the left ventricle. Ann Thorac Surg. 1999;68:131-6.

12. Quigley RL, Weiss SJ, Highbloom RY, Pym J. Creative arterial bypass grafting can be performed on the beating heart. Ann Thorac Surg. 2001;72:793-7.

13. Watanabe G, Takemura H, Tomita S, Misaki T, Hotoh K. Multiple minimally invasive direct $\mathrm{CABG}$ for the complete revascularization: the figure L approach. Thorac Cardiovasc Surg. 2003;51:28-32.

14. Kim KB, Cho KR, Chang WI, Lim C, Ham BM, Kim YL. Bilateral skeletonized internal thoracic artery graftings in off-pump coronary artery bypass: early result of Y versus in situ grafts. Ann Thorac Surg. 2002;74:S1371-6.

15. Kamiya H, Watanabe G, Doi T, Saito T, Takahashi M, Tomita S, et al. Coronary active perfusion system can maintain myocardial blood flow and tissue oxygenation. Eur J Cardiothorac Surg. 2002;22:410-4.

16. Kamiya H, Watanabe G, Doi T, Saito T, Takahashi M, Tomita S, et al. A coronary active perfusion system for off-pump coronary artery 
bypass: advantage over passive perfusion regarding the physiology of the coronary artery. ASAIO J. 2002;48:658-64.

17. Kamiya H, Watanabe G, Doi T, Saito T, Takahashi M, Tomita S, et al. Efficacy and adverse effects of the coronary active perfusion systemfrom a viewpoint of perfusional timing. Ann Thorac Cardiovasc Surg. 2003;9:117-22.

18. Ochi M, Bessho R, Saji Y, Fujii M, Hatori N, Tanaka S. Sequential grafting of the right gastroepiploic artery in coronary artery bypass surgery. Ann Thorac Surg. 2001;71:1205-9.

19. Ochi M, Hatori N, Fujii M, Saji Y, Tanaka S, Honma H. Limited flow capacity of the right gastroepiploic artery graft: postoperative echocardiographic and angiographic evaluation. Ann Thorac Surg. 2001; 71:1210-4

20. Parolari A, Rubini P, Alamanni F, Cannata A, Xin W, Gherli T, et al. The radial artery: which place in coronary operation? Ann Thorac Surg. 2000;69:1288-94.

21. Al-Ruzzeh S, George S, Bustami M, Nakamura K, Khan S, Yacoub M, et al. The early clinical and angiographic outcome of sequential coronary artery bypass grafting with the off-pump technique. $J$ Thorac Cardiovasc Surg. 2002;123:525-30.

22. Sundt TM III, Barner HB, Camillo CJ, Gay WA Jr. Total arterial revascularization with an internal thoracic artery and radial artery $\mathrm{T}$ graft. Ann Thorac Surg. 1999;68:399-405.

23. Jones EL, Lattouf OM, Weintraub WS. Catastrophic consequences of internal mammary artery hypoperfusion. J Thorac Cardiovasc Surg. 1989;98:902-7.

24. Vajatai P, Ravichandran PS, Fessler CL, Floten HS, Ahmad A, Gately $\mathrm{HL}$, et al. Inadequate internal mammary artery graft as a cause of postoperative ischemia: incidence, diagnosis and management. Eur J Cardiothorac Surg. 1992;6:603-8.

25. Uchida N, Kawaue Y. Flow competition of the right gastroepiploic artery graft in coronary revascularization. Ann Thorac Surg. 1996;62: $1342-6$.

26. Sato T, Isomura T, Suma H, Horii T, Kikuchi N. Coronary artery bypass grafting with gastroepiploic artery composite graft. Ann Thorac Surg. 2000;69:65-9. 